\title{
The prevalence of diabetes and metabolic syndrome and associated risk factors in Sudanese individuals with gallstones: a cross sectional survey
}

\begin{abstract}
Ahmed Omer Almobarak ${ }^{1}$, Ayat Jervase ${ }^{2}$, Aza Abdelrahman Fadl ${ }^{2}$, Nur Ibrahim Ali Garelnabi ${ }^{3}$, Suzan Al Hakem ${ }^{4}$, Tarig Mohamed Hussein ${ }^{3}$, Amro Ahmad Aljack Ahmad ${ }^{5}$ Inas Salah El-den Ahmed ${ }^{6}$, Safaa Badi ${ }^{7}$, Mohamed H. Ahmed ${ }^{8}$

${ }^{1}$ Department of Pathology, Faculty of Medicine, University of Medical Sciences and Technology, Khartoum, Sudan; ${ }^{2}$ Public and Tropical Health Program, Graduate College, University of Medical Sciences and Technology, Khartoum, Sudan; ${ }^{3}$ Department of Gastrointestinal Surgery, ${ }^{4}$ Centre of Gastrointestinal and Liver Diseases, Ibn Sina Specialized Teaching Hospital, Khartoum, Sudan; ${ }^{5}$ Medical Services Department, ${ }^{6}$ Health Laboratory Service Unit, Health Insurance Corporation Khartoum State (HICKS), Khartoum, Sudan; ${ }^{7}$ Department of Clinical Pharmacy, Faculty of Pharmacy, Omdurman Islamic University, Khartoum, Sudan; ${ }^{8}$ Department of Medicine and HIV Metabolic Clinic, Milton Keynes University Hospital NHS Foundation Trust, Eagelstone, Milton Keynes, UK

Contributions: (I) Conception and design: AO Almobarak, MH Ahmed; (II) Administrative support: AO Almobarak, A Jervase, AA Fadl, NIA Garelnabi, SA Hakem, TM Hussein, AAA Ahmad, ISE Ahmed; (III) Provision of study materials or patients: AO Almobarak, A Jervase, AA Fadl, NIA Garelnabi, SA Hakem, TM Hussein; (IV) Collection and assembly of data: MH Ahmed, S Badi, AAA Ahmad, ISE Ahmed; (V) Data analysis and interpretation: MH Ahmed, S Badi, AO Almobarak, A Jervase, AA Fadl; (VI) Manuscript writing: All authors; (VII) Final approval of manuscript: All authors.

Correspondence to: Mohamed H. Ahmed. Department of Medicine and HIV Metabolic Clinic, Milton Keynes University Hospital NHS Foundation Trust, Eaglestone, Milton Keynes, Buckinghamshire, UK. Email: elziber@yahoo.com; Mohamed.Hassan-Ahmed@mkuh.nhs.uk.
\end{abstract}

Background: The gallstones are common health problem across the world with huge financial burden on health authorities. Obesity and insulin resistance are associated with risk of gallstones disease (GSD). The aim of this study was to assess the prevalence of metabolic syndrome (MetS) and diabetes and associated risk factors in Sudanese patients with gallstones.

Methods: A prospective cross-sectional study, enrolled patients with gallstones attending Ibn Sina Specialized Teaching Hospital for gastrointestinal and hepatobiliary diseases. A structured questionnaire was applied, anthropometric measures were taken, and blood tested for HbAlc, fasting glucose and lipid profile. Data was analysed using SPSS version 23.

Results: A total number of 151 participants were recruited in the study, 71 of them were ultrasound confirmed GSD patients, and the other 80 were controls without GSD over a period of six months. The prevalence of the MetS and diabetes was 30\% and 23.9\% respectively. Borderline diabetes was $16.9 \%$ and overweight and obesity constituted more than half of the sample 59.6\%. Using Chi-Square test, a statistically significant association was found between MetS and HDL, TG, LDL level, waist circumference and blood pressure (BP). Absolute predictors and the risk factors for gallstone disease were waist circumference, age, HbAlc and LDL.

Conclusions: The prevalence of MetS and diabetes among gallstone patients was 30\% and $23.9 \%$ respectively. Absolute predictors and the risk factors for gallstone disease were waist circumference, age, HbA1c and LDL.

Keywords: Gallstones; obesity; diabetes; metabolic syndrome (MetS); Sudan

Received: 06 August 2019; Accepted: 23 October 2019; Published: 05 April 2020.

doi: $10.21037 / \operatorname{tgh} .2019 .10 .09$

View this article at: http://dx.doi.org/10.21037/tgh.2019.10.09 


\section{Introduction}

Gallstones disease (GSD), metabolic syndrome (MetS) and Obesity are major health challenges for health authorities in both developed and developing countries (1). The overall prevalence of MetS was in range of 20 $25 \%$, though it varies among different populations $(2,3)$. The underlying causes of MetS include overweight and obesity, insulin resistance, an unhealthy dietary pattern, physical inactivity, genetic factors and advanced age (46). Adults with MetS carry two to three times the risk of cardiovascular disease such as heart attack, stroke and death and five times risk of developing type 2 diabetes and a near double risk of developing gallstones (7). On the other hand, gallstones, also known as cholelithiasis, are common benign gastrointestinal disease affecting 10-15\% of people around the world (8). Generally speaking, risk factors for the formation of gallstones were ethnic background, increasing age, female gender, family history, obesity, diabetes mellitus, hyperinsulinism, dyslipidemia, MetS, lack of exercise and with high-calorie diets, rapid weight loss and non-alcoholic Fatty liver $(9,10)$. The rates of gallstone complications are higher in older people and in some ethnic groups, and are also influenced by socioeconomic factors $(11,12)$.

The prevalence of GSD in USA is estimated 15\% (13), and $9-21 \%$ in Europe $(8,14), 5 \%$ in Ethiopia and 5.2 in Sudan in 1994 (15). Interestingly, in Sudanese population pigment stones were most prevalent and that gall stones were more frequent in women aged between 40-49 years (16). GSD are common presentation in the Sudanese surgical departments, usually diagnosed and surgically treated, but little is known about cholelithiasis in Sudan, its prevalence, risk factors and metabolic associations. Therefore, the aim of the current study was to assess the prevalence of MetS and diabetes among patients with gallstone and associated risk factors.

\section{Methods}

\section{Study design}

A prospective, cross-sectional, hospital-based study. The study was conducted at Ibn Sina Specialized Teaching Hospital for gastrointestinal, hepatobiliary diseases and urology in capital city of Sudan, Khartoum. It serves patients from almost all parts of the country. The study population was patients attending the Hospital between May and December 2018.

\section{Inclusion criteria}

The cases group were participants attending the outpatient department (OPD)/Referred Clinic in Ibn Sina Hospital scheduled for cholecystectomy from the period of May till December 2018 and those with Ultrasound confirmed cholelithiasis/gallstone and the control group were crossmatched patients without gallstone disease. Patients aged 18 years and above and those who agreed to participate in the study. Patients with hematological disorders (sickle cell disease, thalassemia), patients with chronic liver disease (cirrhosis, hemochromatosis), pregnant women and patients who were on statins were excluded from the study.

\section{Sample size and sampling technique}

A purposive convenient sampling technique was used. sample size was calculated based on an expected prevalence between $(5.2 \%)$ to guide the sample saturation stage to reach a $95 \%$ confidence interval. Therefore, 76 patients with gallstone were sequentially enrolled in accordance to their informed consent.

The equation used for the sample size calculation is:

$\mathrm{n}=\mathrm{Z}^{2} \mathrm{P}(1-\mathrm{P}) / \mathrm{d}^{2}$

Whereas:

$\mathrm{n}$ is the sample size, $\mathrm{Z}$ is the statistic corresponding to level of confidence assumed $95 \%$ confidence interval, $\mathrm{P}$ is expected prevalence estimated at (5.2\%) reference, $\mathrm{d}$ is precision (corresponding to effect size).

$$
\mathrm{n}=\frac{(1.96)^{2} \times 0.052(1-0.052)}{(0.05)^{2}}=75.75
$$

i.e., 76 patients with gallstone

Besides that, we selected other 80 participants and considered them as a control group which had the same characteristics of the cases group (cross-matching) except for gallstone disease, so the total sample size in this study was 156 participants.

\section{Data collection methods}

About 151 Sudanese patients participated in the study, the response rate was $96.7 \%$. Interview guided structured questionnaire was administered containing personal information, medical history, laboratory finding on basic metabolic profile and ultrasonography findings. Information on basic metabolic profile are requested pre-operatively by the surgeon [liver function test, renal function test (including electrolytes) and fasting blood glucose (FBG), 
Table 1 Socio-demographic characteristics among studied participants $(\mathrm{n}=151)$

\begin{tabular}{lccc}
\hline Variable & & N & $\%$ \\
\hline Gender & Male & 25 & 16.6 \\
& Female & 126 & 83.4 \\
Residence & Urban & 97 & 64.2 \\
& Rural & 54 & 35.8 \\
Marital status & Married & 76 & 50.3 \\
& Single & 65 & 43.0 \\
& Divorced & 2 & 1.3 \\
BMl & Widowed & 8 & 5.3 \\
& Under weight & 8 & 5.3 \\
& Normal weight & 53 & 35.1 \\
& Overweight & 53 & 35.1 \\
& Obese & 37 & 24.5 \\
\hline
\end{tabular}

BMI, body mass index.

lipid profile, and HbA1c]. In addition, all participants were offered abdominal ultrasonography in order to meet the criteria for 'Ultrasound confirmed cholelithiasis' by a senior expert specialist in Ibn Sina Hospital. Structured questionnaire was used to collect data for sociodemographic data. Stethoscope and sphygmomanometer, measurement tape, weighing scale, height scale, and calculator, were used for measurement of blood pressure (BP), body mass index (BMI) and waist circumference. The reference values used to determine the diabetic status was obtained from the standard NICE guidelines; HbA1c below $5.7 \%$ was considered non diabetic range, $5.7-6.4 \%$ was pre-diabetic and $6.5 \%$ or higher was diagnostic for diabetes.

MetS was defined if three out of five criteria of the standard adult treatment panel (ATP) III were met, namely (I) Waist $>102 \mathrm{~cm}$ in males and $>88 \mathrm{~cm}$ in females; (II) serum TG $>150 \mathrm{mg} / \mathrm{dL}$, OR being treated for hypertriglyceridemia; (III) serum HDL $<40 \mathrm{mg} / \mathrm{dL}$ in males and $<50 \mathrm{mg} / \mathrm{dL}$ in females, OR being treated for low HDL level; (IV) BP $>130 / 85 \mathrm{mmHg}$, OR being treated for high BP; (V) FPG $\geq 110 \mathrm{mg} / \mathrm{dL}$, OR being treated for high blood sugar.

\section{Data analysis}

Data was analysed using SPSS version 23, Descriptive statistics (frequency tables, means and standard deviations) and inferential statistics (Chi-square test and logistic regression analysis) were used.

\section{Ethical consideration}

It was sought from SUMASRI Institutional Review Board (SIRB) as well as the Ibn Sina Institution Research committee.

\section{Results}

\section{Socio-demographic characteristics}

The study enrolled 151 patients, 71 (47.0\%) of them had gallstone disease, and 80 control without gallstones. Majority (83.4\%) were females. The mean age was $51.5 \pm 14.7$. Married patients made up $50.3 \%$ of the study population, followed by single $43.0 \%$, widowed $5.3 \%$ and divorced $1.3 \%$.

In this study, the number of patients with normal weight were equal to those with overweight (35.1\%), while obese patients were $24.5 \%$. The two categories of overweight and obese constituted above half of the sample $59.6 \%$. while only $5.3 \%$ of them were categorized as underweight $(n=8)$ (Table 1).

\section{The prevalence of diabetes among participants with GSD}

The fasting blood glucose (FBG) was reported high in $49.7 \%$ of the total participants and in $39.4 \%(n=28)$ among the participants with GSD. HbA1c was used to classify the patients with GSD into diabetic, pre-diabetic and nondiabetic. Diabetes was found in $23.9 \%(n=17)$ among participants with GSD (Table 2). When performed Chisquare test, the only significant result was found between diabetes and LDL level $(\mathrm{P}=0.002)$.

\section{Lipid profile among GSD patients}

High cholesterol was reported in $23.9 \%$, while high TG was also seen in $21.1 \%$. Low HDL-cholesterol was reported in $33.8 \%$ of the female and only in $2.8 \%$ of male (Table 2 ).

\section{BP among patients with GSD}

About 27\% ( $n=19)$ of the GSD participants were found to have high BP. A total of $25 \%(n=18)$ of the respondents with GSD reported that they were formerly diagnosed with hypertension and being treated for high $\mathrm{BP}$ at the time of the gall stone operation. 
Table 2 Distribution of FBG, HbA1c, and lipid profile among participants with GSD (n=71)

\begin{tabular}{llcc}
\hline Variables & & $\mathrm{N}$ & $\%$ \\
\hline FBG & Normal $(<110 \mathrm{mg} / \mathrm{dL})$ & 43 & 60.6 \\
& High $(\geq 110 \mathrm{mg} / \mathrm{dL})$ & 28 & 39.4 \\
& High $(>6.5 \%)$ & 17 & 23.9 \\
Cholesterol & Normal $(<6.5 \%)$ & 54 & 76.1 \\
& Normal $(<200)$ & 54 & 76.1 \\
TG & High $(\geq 200)$ & 17 & 23.9 \\
& Normal $(<150)$ & 56 & 78.9 \\
HDL & High $(\geq 150)$ & 15 & 21.1 \\
& Normal & & \\
& M $(\geq 40)$ & 9 & 12.7 \\
& F $(\geq 50)$ & 36 & 50.7 \\
& Low & & \\
& F $(<50)$ & 24 & 33.8 \\
& M $(<40)$ & 2 & 2.8 \\
& Normal $(<100 \mathrm{mg} / \mathrm{dL})$ & 30 & 42.3 \\
& High $(\geq 100 \mathrm{mg} / \mathrm{dL})$ & 41 & 57.7 \\
\hline
\end{tabular}

FBG, fasting blood glucose; GSD, gallstones disease.

\section{The prevalence of MetS among participants with GSD}

In this study, MetS was diagnosed in $30 \%(n=21)$ of patients with GSD. The number of metabolic abnormalities was variable from five to none among all GSD patients included in this study. Diagnosis of MetS was made if three out of five metabolic parameters were abnormal according to the ATP III criteria.

\section{Test of associations}

\section{Chi-square test}

(I) MetS was significantly associated with $\mathrm{HbA1c}$ ( $\mathrm{P}=0.027)$, BP $(\mathrm{P}=0.001)$, HDL $(\mathrm{P}=0.008)$, TG $(\mathrm{P}=0.004)$, LDL $(\mathrm{P}=0.013)$ and waist circumference $(\mathrm{P}=0.000)$ but the association between $\mathrm{BMI}$ and MetS was statistically insignificant $(\mathrm{P}=0.323)$;

(II) The association between GSD with waist circumference, BP, HbA1c and LDL was statistically significant $(\mathrm{P}=0.000,0.002,0.001,0.000)$ respectively.

\section{Logistic regression}

(I). MetS was associated with higher odd ratio in relation to gender, HbA1c and BMI (Table 3). For instance, females with GSD are more exposed to develop MetS by about 5 times more than their counterparts' males (odd ratio $=4.848$ ), similarly, uncontrolled HbA1c contribute in the development of MetS by approximately 3 times than the controlled HbA1c. Also being an overweight or obese patient, this may increase the probability of getting MetS by approximately 2 times than those who have normal weight or underweight (odd ratio 1.950) (Table 3);

(II). When logistic regression was performed to determine the predictors and the risk factors for gallstone disease, we found that, waist circumference, age, HbAlc and LDL had a significant association with the presence of GSD ( $\mathrm{P}=0.013,0.022,0.000,0.000)$ respectively. Furthermore, LDL was a strong predictor for the GSD, in other words, uncontrolled LDL level may predict the presence of GSD by approximately 17.5 times more than the controlled. Similarly, increased waist circumference is more likely to contribute to GSD by approximately 3.7 times than the normal level. although there are insignificant associations, between GSD and BP and MetS, but the presence of MetS, as well as the increased BP level are more likely to contribute to the presence of GSD by approximately 1.6 times than those hadn't Met and had normal BP (Table 4).

\section{Discussion}

Obesity is an important risk factor for diabetes, MetS and gallstones. In this study, patients who were in the overweight zone constituted $35 \%$, while obese patients were $24 \%$, and the two categories constituted more than on half of the sample $59 \%$.Several studies showed that overweight and obesity are main risk factors for MetS (4-6). The prevalence of MetS in this study was found to be $30 \%$ of patients with gallstones. MetS and insulin resistance are an important factors that lead to the formation of gallstones (17). Therefore, it is not surprising that the global prevalence of MetS was estimated to be in the range of $23-25 \%(18,19)$. Sasazuki et al. also showed that glucose intolerance is associated with a modest increase in the risk 
Table 3 the predictors of MetS among GSD patients by using logistic regression test $(\mathrm{n}=71)$

\begin{tabular}{lccccc}
\hline Variable & B & S.E. & $\chi^{2}$ & P value & Odd ratio \\
\hline Age in Years & -0.047 & 0.027 & 3.11 & 0.078 & 0.954 \\
Gender & 1.579 & 0.979 & 2.599 & 0.107 & 0.204 \\
HbA1c & 1.111 & 0.875 & 1.614 & 0.361 & 0.548 \\
BMl & 0.668 & 1.111 & 4.251 & 0.039 & 1.950 \\
Constant & 3.866 & 1.875 & 47.754 & \\
\hline
\end{tabular}

MetS, metabolic syndrome; GSD, gallstones disease; BMI, body mass index.

Table 4 the predictors of GSD by using logistic regression test $(\mathrm{n}=151)$

\begin{tabular}{lccccc}
\hline Variable & B & S.E. & $\chi^{2}$ & P value & Odd ratio \\
\hline Waist circumference & 1.308 & 0.529 & 6.107 & 0.013 & 0.698 \\
Age in Years & -0.034 & 0.015 & 5.219 & 0.022 & 0.485 \\
MetS & 0.490 & 0.702 & 0.488 & 0.000 & 0.633 \\
HbA1c & -2.764 & 0.669 & 17.081 & 18.310 & 0.000 \\
LDL & 2.862 & 0.669 & 0.876 & 0.349 & 17.492 \\
BP & 0.481 & 0.514 & 1.715 & 0.190 & 1.618 \\
Constant & 0.996 & 0.761 & & 2.707 \\
\hline
\end{tabular}

GSD, gallstones disease; MetS, metabolic syndrome; BP, blood pressure.

of gallstone disease (20). Pacchioni et al. showed that obesity is a stronger risk factor for gallstones than type $2 \mathrm{DM}$ (21). However, the prevalence of gallstone among diabetic patients in Nigeria was found to be $17.5 \%$ (22). Importantly, in China the risk of cholelithiasis increases with the number of components of MetS for males but not for females (23). Nahum Méndez-Sánchez et al. showed that MetS was associated with more than three-fold risk of gallstone disease (24). In Iran, it was shown that individuals with MetS had 2.2 times more occurrence of gallstones in both gallbladder and biliary tract than patients without MetS (25). Furthermore, Tsai et al. found that the risk of cholelithiasis is directly affected by the number of metabolic abnormalities in a nondiabetic population (26). In this study MetS was associated with 1.6 times more occurrence of gallstones.

Importantly, MetS has been observed to place people at increased risk for developing diabetes mellitus and cardiovascular disease as well as increased mortality from cardiovascular disease (27). In this study, the prevalence of diabetes mellitus among GSD patients was $23.9 \%$ while in the study done by Hazari et al., the prevalence was slightly higher $35.5 \%$ (28). Several studies showed the association between GSD and diabetes and these were listed in the review by Ahmed et al. (10).

Risk factors for the formation of gallstones were ethnic background, increasing age, female gender, family history, obesity, diabetes mellitus, hyperinsulinism, dyslipidemia, MetS, lack of exercise and with high-calorie diets, rapid weight loss and non-alcoholic Fatty liver $(9,10)$.

In this study, we showed that waist circumference, age, HbA1c and LDL were important risk factors for gallstone formation.

This study is not without limitations. The patients were recruited from single center and this may not represent all population living in Sudan. Furthermore, different tribes are living in Sudan and have different dietary habits. Therefore, future studies should address all these concerns. Despite these limitations our study is novel and showed high prevalence of both MetS and diabetes among cohort population with gallstones.

\section{Conclusions}

The prevalence of MetS and diabetes among gallstone 
patients was $30 \%$ and $23.9 \%$ respectively. Absolute predictors and the risk factors for gallstone disease were waist circumference, age, HbA1c and LDL.

\section{Acknowledgments}

This study was funded by Health Insurance Corporation Khartoum State (HICKS), Sudan. Authors would like to acknowledge the incredible support of all staff at Ibn Sina Specialized Teaching Hospital.

\section{Footnote}

Conflicts of Interest: The authors have no conflicts of interest to declare.

Ethical Statement: The authors are accountable for all aspects of the work in ensuring that questions related to the accuracy or integrity of any part of the work are appropriately investigated and resolved. The study was approved by the SUMASRI Institutional Review Board and Ibn Sina Institution Research committee (00008867).

\section{References}

1. Acalovschi M, Lammert F. The Growing Global Burden of Gallstone Disease. Available online: https://www. worldgastroenterology.org/publications/e-wgn/e-wgnexpert-point-of-view-articles-collection/the-growingglobal-burden-of-gallstone-disease

2. Grundy SM, Brewer Jr HB, Cleeman JI, et al. Definition of metabolic syndrome: report of the National Heart, Lung, and Blood Institute/American Heart Association conference on scientific issues related to definition. Circulation 2004;109:433-8.

3. The IDF consensus worldwide definition of the metabolic syndrome. International Diabetes Federation Brussels, 2005.

4. Shaffer EA. Epidemiology and risk factors for gallstone disease: has the paradigm changed in the 21 st century? Curr Gastroenterol Rep 2005; 7:132-40.

5. Schirmer BD, Winters KL, Edlich RF. Cholelithiasis and cholecystitis. J Long Term Eff Med Implants 2005;15:329-38.

6. Tazuma S. Epidemiology, pathogenesis, and classification of biliary stones (common bile duct and intrahepatic). Best Pract Res Clin Gastroenterol 2006;20:1075-83.

7. Alberti KGMM, Zimmet P, Shaw J. Metabolic syndrome- -a new world-wide definition. A Consensus Statement from the International Diabetes Federation. Diabet Med 2006;23:469-80.

8. Stinton LM, Shaffer EA. Epidemiology of gallbladder disease: cholelithiasis and cancer. Gut Liver 2012;6:172.

9. Acalovschi M, Buzas C, Radu C, et al. Hepatitis $\mathrm{C}$ virus infection is a risk factor for gallstone disease: a prospective hospital-based study of patients with chronic viral C hepatitis. J Viral Hepat 2009;16:860-6.

10. Ahmed MH, Barakat S, Almobarak AO. The association between renal stone disease and cholesterol gallstones: the easy to believe and not hard to retrieve theory of the metabolic syndrome. Ren Fail 2014;36:957-62.

11. Diehl AK, Rosenthal M, Hazuda HP, et al. Socioeconomic status and the prevalence of clinical gallbladder disease. J Chronic Dis 1985;38:1019-26.

12. Freeman J, Boomer L, Fursevich D, et al. Ethnicity and insurance status affect health disparities in patients with gallstone disease. J Surg Res 2012;175:1-5.

13. Everhart JE, Ruhl CE. Burden of digestive diseases in the United States Part III: Liver, biliary tract, and pancreas. Gastroenterology 2009;136:1134-44.

14. Aerts R, Penninckx F. The burden of gallstone disease in Europe. Aliment Pharmacol Ther 2003;18:49-53.

15. Getachew A. Epidemiology of gallstone disease in Gondar University Hospital, as seen in the department of radiology. Ethiop J Health Dev 2008;22:7.

16. Idris SA, Elsiddig KE, Hafiz MM, et al. Minerals' composition of different types of gallstones in Sudanese population. Open Sci J Anal Chem 2014;1:1-5.

17. Biddinger SB, Haas JT, Bian BY, et al. Hepatic insulin resistance directly promotes formation of cholesterol gallstones. Nature Med 2008;14:778.

18. Ford ES, Giles WH, Dietz WH. Prevalence of the metabolic syndrome among US adults: findings from the third National Health and Nutrition Examination Survey. JAMA 2002;287:356-9.

19. Ford ES, Giles WH. A comparison of the prevalence of the metabolic syndrome using two proposed definitions. Diabetes Care 2003;26:575-81.

20. Sasazuki S, Kono S, Todoroki I, et al. Impaired glucose tolerance, diabetes mellitus, and gallstone disease: an extended study of male self-defense officials in Japan. Eur J Epidemiol 1999;15:245-51.

21. Pacchioni M, Nicoletti C, Caminiti M, et al. Association of obesity and type II diabetes mellitus as a risk factor for gallstones. Digestive diseases and sciences 2000;45:2002-6.

22. Agunloye AM, Adebakin AM, Adeleye JO, et al. 
Ultrasound prevalence of gallstone disease in diabetic patients at Ibadan, Nigeria. Niger J Clin Pract 2013;16:71-5.

23. Zuo H, Shi Z, Hu X, et al. Prevalence of metabolic syndrome and factors associated with its components in Chinese adults. Metabolism 2009;58:1102-8.

24. Méndez-Sánchez N, Chavez-Tapia NC, Motola-Kuba $\mathrm{D}$, et al. Metabolic syndrome as a risk factor for gallstone disease. World J Gastroenterol 2005;11:1653.

25. Alizadeh AHM, Khah MM, Damghani NS, et al. Metabolic Syndrome in Patients with Gallstone. J Liver 2013. doi:10.4172/2167-0889.1000138.

doi: $10.21037 / \operatorname{tgh} .2019 .10 .09$

Cite this article as: Almobarak AO, Jervase A, Fadl AA, Garelnabi NIA, Hakem SA, Hussein TM, Ahmad AAA, Ahmed ISE, Badi S, Ahmed MH. The prevalence of diabetes and metabolic syndrome and associated risk factors in Sudanese individuals with gallstones: a cross sectional survey. Transl Gastroenterol Hepatol 2020;5:14.
26. Dalvand S, Niksima SH, Meshkani R, et al. Prevalence of Metabolic Syndrome among Iranian Population: A Systematic Review and Meta-analysis. Iran J Public Health 2017;46:456.

27. Tsai CH, Wu JS, Chang YF, et al. The number of metabolic abnormalities associated with the risk of gallstones in a non-diabetic population. PloS One 2014;9:e90310.

28. Hazari MAH, Taskeen S. Observational study on the prevalence of diabetes mellitus among ultrasonographically diagnosed cholelithiasis patients. Int J Clin Exp Physiol 2016;3:77-81. 